\title{
The Big Bang Refuted and Some Problems in Metaphysics and Epistemology Solved
}

\author{
Kenneth Cust* \\ University of Central Missouri, USA
}

*Corresponding author: Kenneth Cust, University of Central Missouri, USA, Tel: 660-221-
Conceptual Paper

Volume 4 Issue 2

Received Date: March 24, 2021

Published Date: May 05, 2021

DOI: $10.23880 /$ phij-16000174
Will Durant was a giant of the freethought movement, ${ }^{1}$ a philosopher, historian, Pulitzer Prize winner, recipient of the Presidential Medal of Freedom, and author of the monumental eleven volumes of The Story of Civilization, as well as several other works. The work was originally conceived to be written in five volumes ${ }^{2}$ but was expanded to eleven as, the Durants tell us, "the Reaper repeatedly overlooked us." ${ }^{3}$ In a later work he tells us that It's unphilosophical for a human being who is a mere microscopic part of the universe, to think he can ever understand the universe, so that the first lesson of philosophy is to see yourself in perspective and therefore give up the notion that you're ever going to explain who made the world or where it's going --- you put those things behind you. ${ }^{4}$

I beg to differ with Durant's "first lesson of philosophy." The "universe" can be understood logically. That is, using basic logic I can explain how the universe came to be what it is now, how life began, and what will happen in the future. In addition, I will show how this begins to spell the end

1 The history of the free thought movement has been admirably traced by Samuel P. Putnam in his 400 Years of Freethought, The Truth Seeker Company, New York, 1894. He traces the free thought movement from the year 1600. George E. Macdonald continues the history of the free thought movement in his 2 volume Fifty Years of Freethought, The Truth Seeker Company, New York, 1929-1931. This work traces the history of the free thought movement from 1875 through to 1925.

2 Durant Will. The Story of Civilization. Simon and Schuster, New York, Volume 1, p. viii.

3 Ibid, Volume 11, p. vii.

4 Durant Will. An Invitation to Philosophy. (Compiled and edited by Jon Little), Promethean Press, Dallas, Ontario, 2003, p. 76. Italics in the original. This quote can also be found in Durant's Adventures in Philosophy. (Compiled and edited by John Little), Promethean Press, Carrolton, TX, 2008, p. 33. to some problems of metaphysics and epistemology.

In the course of offering these explanations it will be necessary to refute the so-called "big bang" theory of the origin of the universe. However, before I prove that the big bang theory of the origin of the universe cannot possibly be true, I must first set the proper context in which the argument has to take place. Sir Isaac Newton is reported to have written "If I have seen further it is by standing on the shoulders of Giants." ${ }^{15}$ Listing the giants on whose shoulders I have stood before reaching my conclusions would involve writing a history of philosophy, a task beyond the scope of this paper. I would note, however, that I followed Lord Macaulay's advice of reading the books that "moved the intellects which have moved the world"6 and in the course of doing so I lost my "Intellectual Virginity." It was by standing on the shoulders of giants that enabled me to prove that Thomas Paine was the author of the "Junius Letters" 8 and that Anne Boleyn was the biological daughter of Henry VIII. ${ }^{9}$ So, for my present purposes, a simple reiteration of the observation that "a dwarf standing on the shoulders of a giant may see farther

5 Bartlett's Familiar Quotations, Seventeenth Edition, Little, Brown and Company, New York, 2002, p. 290. He wrote this line in a letter to Robert Hooke, dated February 5, 1675-76.

6 Lady Trevelyan, editor. The Miscellaneous Works of Lord Macaulay, Whitehall Edition, G. P. Putnam's Sons, New York, 1898. Volume 4, p. 162.

7 The phrase "Intellectual Virginity" is trademarked by Philosophical Services, LLC. See

http://intellectualvirginity.com/.

8 Junius Unveiled. American International Journal of Social Science, Vol. 3, No. 1. January 2014, pp. 51- 58. See http://aijssnet.com/journals/Vol_3_ No_1_January_2014/5.pdf.

9 Who Was Anne Boleyn? American International Journal of Social Science, Vol. 7, No. 1, March 2018, pp. 50-55. See http://aijssnet.com/journals/ Vol_7_No_1_March_2018/7.pdf. 


\section{Philosophy International Journal}

than a giant himself,"10 along with the arguments presented below, will have to suffice.

There are four ideas that are necessary for understanding the arguments I will make. These four ideas are the logic of quantification, necessary and sufficient conditions, logically necessary concepts, and the difference between universals and particulars. While philosophers are generally knowledgeable about these ideas, non-philosophers may not be, so I explicate them below.

Quantification --- which was discovered by Frege and Michael Dummett calls Frege's discovery "the deepest single technical advance ever made in logic"11 --- is quite simple. It involves the number of things that belong to any given class: All, Some or None. This means that there only three things that can be said logically about things in any given class. For example, if we are talking about the class of human beings who are mortal we can, logically, only say that either "All humans are mortal" or "Some humans are mortal" or "No humans are mortal." "All," literally, means all. "Some" means at least one and less than all. And "none" means, again literally, none.

When it comes to having sex, some men, and women, set aside their reasoning. An amusing story is told about Aristotle. As the story goes, it seems Aristotle was smitten by a young woman. He pleaded with her to go on a date with him. She kept refusing him. Finally, he said: "If you go on a date with me I will do anything you want." She is reported to have replied: "Anything"? Aristotle is reported as saying: "Yes. Anything." She then told him to strip naked, which he did. She put a bridle and saddle on him and rode him around the agora (the modern equivalent being our farmer's markets). He put up with this humiliating venture for a short while but then quit. It has been said --- I know because I said it --- he then went and discovered logic. ${ }^{12}$

What does "anything" mean, logically? It can mean only one of three things: All, Some, or None. In this case, and in all cases, it means all. Applying quantification to the idea of necessary and sufficient conditions ${ }^{13}$ we can say there are necessary and sufficient conditions for all things, ${ }^{14}$ for some

10 Democritus Junior (Pseudonym, Robert Burton). 2004. The Anatomy of Melancholy, Project Gutenberg Edition, EBook \#10800.

11 Copi, Irving M. and Cohen, Carl, Introduction to Logic, 8th edition, Macmillan Publishing Company, New York, 1990, p.324.

12 Brewer, Cobham E. The Reader's Handbook, Chatto and Windus, Piccadilly, London, 1885, 5th Edition, p. 52.

13 More information on necessary and sufficient conditions can also be found in any logic textbook.

14 I am using the word "things" generically to include things as well as events. things, or for no things. Obviously there must be necessary and sufficient conditions for all things; for if there were not necessary and sufficient conditions for all things, then --- for those things without necessary and sufficient conditions --- nothing would change. While we may not know what the necessary and sufficient conditions actually are, we do know that there are necessary and sufficient conditions for all things. For example, I do not know what the actual necessary and sufficient conditions are for you to be reading this article, but I do know that if you are reading these words, then the necessary and sufficient conditions have been satisfied.

Logically necessary concepts are concepts that cannot be denied ${ }^{15}$ without absurdity. For example, I tell my students on the first day of class that I know more about their sex lives than they think, even though I have never met any of them. They, of course, deny this for the reason --- as one student put it --- "that since I do not know them I cannot know anything about their sex lives." That is, they have no understanding about the idea of logically necessary concepts. I tell them that if they had sex, they had it some where and at some time and with some one. Putting out "the sacred fire," to use the modern vernacular, ${ }^{16}$ is an age-old tradition. While one might argue about the number of men Cleopatra is reported to have put out the sacred fire with in one night, "no less than one hundred and six men in one night,"17 one cannot argue with the facts that if she had sex she had it some where, at some time, and with some one. To argue against these logically necessary concepts one would not simply be "utter[ing] nonsense learnedly," ${ }^{18}$ one would be placing "himself beyond all reach of a reductio ad absurdum." ${ }^{19}$

That people of all ages believe absurdities especially when it comes to putting out the sacred fire, such as the existence of twelve foreskins of Jesus ${ }^{20}$ or that one of these foreskins became aroused at the sight of a young naked girl and "ascended, like Jesus himself, and expanded into one of the rings of Saturn."21 The Lockean maxim is that "reason

15 Logically necessary concepts are like Locke's primary qualities. Cf John Locke, An Essay Concerning Human Understanding, Dover Publications, Inc., New York, 1959, Vol. 1, pp. 169-170.

16 Goldberg, B. Z. The Sacred Fire: A History of Sex in Ritual, Religion and Human Behavior. Horace Liveright, New York, 1930.

17 Stone, Lee Alexander. The Power of a Symbol. Pascal Covici, Chicago, 1925, p. p. 112.

18 Durant, Will. The Story of Philosophy, Ernest Benn, Ltd., London, 1926, p. 565.

19 Stephen, Leslie. History of English Thought in the Eighteenth Century. Smith, Elder, \& Co., London, 1876, p. 440.

20 Stone, Lee Alexander. The Power of a Symbol. Pascal Covici, Chicago, 1925, p. 32.

21 Foote, G. W. and Wheeler, J. M. The Crimes of Christianity, Progressive Publishing Company, London, 1887. p. 94. 


\section{Philosophy International Journal}

must be our last judge and guide in everything."22 Here I conjoin Locke's maxim with Hittell's maxim that "in such controversies," he writes the maxim "is fiat justitia, ruat coelum [let us know the truth, though it send us to hell.]"23

Lucian of Samosata --- who lived in the 2nd century A. D. --- hinted at the notion of logically necessary concepts when he wrote about what some of his contemporaries had to say about the creation of the universe. He wrote as follows:

Some say it had no beginning, and cannot end; others boldly talk of its creator and his procedure; what particularly entertained me was that these latter set up a contriver of the universe, but fail to mention where he came from, or what he stood on while about his elaborate task, though it is by no means obvious how here could be place or time before the universe came into being. ${ }^{24}$

Lucian did not understand "how there could be place or time before the universe came into being" because of two mistakes in his reasoning. The first mistake is that while he may have stood on the shoulders of giants to have hinted at the idea of logically necessary concepts, he did not see far enough to identify them. His second mistake is that he did not see far enough to recognize that the universe is not a thing; it is an abstract concept, a universal. It is defined as everything that exists, whether known or unknown.

Logic tells us there can be only one "everything that exists." That is, logically there cannot be "multiple universes" or --- as some physicists call them --- "multiverses" or "parallel or baby universes." ${ }^{25} \mathrm{~A}$ second example will also prove our claim that non-hilosophers do not understood logic. This example is from the 19th century and concerns a claim made by some Christians. In a question and answer format on what Christians ought to believe about their religion we find the following question and answer:

Question 185: Did the Most Holy Mary remain, in fact, ever a virgin? Answer: She emained and remains a virgin before the birth, during the birth, and after the birth of the Savior; and therefore is called ever-virgin. ${ }^{26}$

22 Locke, John. An Essay Concerning Human Understanding, Dover Publications, Inc. New York,1959, p. 438.

23 Hittell, John S. The Evidences Against Christianity, Calvin Blanchard, New York, 1857, p. 7.

24 Lucian. The Works of Lucian of Samosata, Translated by H. W. Fowler and F. G. Fowler, Clarendon,1905, Volume 3, p 130.

25 Hawking, Stephen. A Brief History of Time. The Illustrated Updated and Expanded Edition. Bantam Books, New York, 1996, p. 243. There are many other physicists who believe in such things as a quick internet search will demonstrate.

26 Schaff, Philip. The Creeds of Christendom, Harper \& Brothers, New York, Volume 2, pp. 471-472. Italics in the original.
Logic tells us that any women who has had a child is not a virgin. The third law of logic, the law of non-contradiction, tells us two propositions cannot be both true and false at the same time and in the same respect. My first thought on reading the quotation above was the old adage, reportedly attributed to Mark Twain, that "it is better to be silent and thought a fool than to speak up and remove all doubt".

In addition, since the universe is not a thing, but rather a concept it is neither infinite nor finite. Some writers think it is an either/or proposition. Dixon, in writing about Einstein's calculation of the size of the universe, writes "Anyone of us can tell [if the universe is infinite or finite], even you and I, that it is one or the other." ${ }^{\prime 27}$ No it is neither; the universe is a concept and not a thing and, therefore, it is neither infinite nor finite. Einstein was wrong as well in attempting to calculate the size of the universe and for the same reason. The universe, as a concept, has no size. It would be like asking "how big is furniture?" Furniture, as a concept, has no size. Tables and chairs have size but furniture, again, as a concept, has no size.

Philosophers make a distinction between universals and particulars, abstract ideas and particular things and it dates back to Plato and Aristotle. This debate is sometimes called "The Problem of Universals." ${ }^{28}$ Durant writes that it was the great battlefield on which Aristotle fought out with Plato the dread question of universals"; it was the first conflict in a war which was to last till our own day, and make all medieval Europe ring with the clash of "realists" and "nominalists." 29

Disraeli tells us that "nothing could exceed the violence with which these disputes were conducted." He cites a witness of their violence:

when the contending parties had exhausted their stock of verbal abuse, they often came to blows; and it was not uncommon in these quarrels about universals, to see the combatants engaging not only with their fists, but with clubs and swords, so that many have been wounded and some killed. ${ }^{30}$

It does not matter whether the realists --- who believe that universals actually exist, as in Plato's World of Forms

27 Dixon, W. Macneile. The Human Situation, Longmans, Green \& Co., New York, 1937, p. 168.

28 Flew, Antony. An Introduction to Western Philosophy. Thames and Hudson. 1989, p. 443. Italics in the orginal.

29 Durant, Will. The Story of Philosophy. Ernest Benn, Ltd., London, 1926, p. 69 Durant notes in a footnote that "It was in reference to this debate that Friedrich Schlegel said, "Every man is born either a Platonist or an Aristotelian."

30 Disraeli, Isaac. Curiosities of Literature, William Veazie, Boston, 1859, Vol. 1, p. 407.Italics in the original. 


\section{Philosophy International Journal}

--- or the nominalists ---who believe that universals are merely words that cover a class of things --- are right for my argument does not rest on who is right in this debate. Ideas, whether they exist or not, do not have size. This is what philosophers call a category mistake. ${ }^{31}$

Aristotle tells us that when the pre-Socratics began to philosophize they wondered originally at the obvious difficulties, then advanced little by little and stated difficulties about greater matters, e.g., about the phenomena of the moon and those of the sun and stars, and about the genesis of the universe. ${ }^{32}$

There have been numerous accounts throughout history of the so-called "genesis of the universe." 33 The account offered in the Old Testament is that "in the beginning God created heaven, and earth." In my Catholic Bible there is a footnote following this quote. It read as follows:

Chap. 1. Ver. 1. Created. The Hebrew word here means to create out of nothing. The account of the six days of creation, given in Chapter 1, poses some problem when it is compared with natural science. [...] All Catholics must hold that the biblical account of creation is an historical document, and not a myth or a fable. ${ }^{34}$

That is, as a Catholic I must hold that God created the universe out of nothing. But this is logically impossible for it commits the fallacy of the stolen concept.

This fallacy was first identified by Leslie Stephen when he criticized Hume's argument on the grounds "that we cannot conceive of a non-magnetic magnet." ${ }^{35}$ This fallacy occurs when someone uses a concept but then denies some, or all, of the concepts that logically depend on it. Denying the magnetic property of a magnet is to commit this fallacy. Descartes' cogito ergo sum is also an example of this fallacy because he

31 Angeles, Peter. Dictionary of Philosophy, Barnes and Noble Books, New York, 1981, p. 31. The author explains category mistakes as follows; "The improper semantical grouping of unrelatable classes of meaning which results in some form of ABSURD (meaningless, ridiculous, nonsensical "sound without sense") statement; no literal meaningful translation of the statement is possible which can avoid the absurdity. Example: "The redness of time hits until it sleeps." This sentence is syntactically (grammatically) but not semantically legitimate due to category mistakes." Emphasis in the original.

32 Aristotle, Metaphysics, 982b15.

33 Koestler, Arthur. The Sleep Walkers: A History of Man's Changing Vision of the Universe, The Macmillan Company, New York, 1959.

34 The Holy Bible, The Catholic Press, Inc. Chicago, 1950, p. 1.

35 Stephen, Leslie. History of English Thought in the Eighteenth Century, Smith, Elder \& Co., London, 1876, Vol. 1, p. 53.While Stephen may have first identified this fallacy he did not name it. Ayn Rand was the first to name it the fallacy of the stolen concept. Cf The Ayn Rand Lexicon, edited by Harry Binswanger, New American Library, New York, 1986, p. 478. says he is "a thing which thinks." But a thing has size, shape, location and the mind has none of these. Pope John Paul II also committed this fallacy when he stated to an audience at the Vatican that "rather than a place, hell indicates the state of those who freely and definitively separate themselves from God." ${ }^{36}$ If you exist you must exist somewhere. Location is a logically necessary concept and to deny it commits this fallacy. Some physicists also commit this fallacy when they claim to be studying the physics of nothing. ${ }^{37}$ If there really was nothing --- that is, the total absence of everything --there would be no physicists around to study it. As to the philosophical question raised in this article: "Why is there something rather that nothing at all?" The answer is really quite simple. If there ever was a time when nothing existed, nothing would exist now. Why would this be true? Because you cannot get something from nothing. Nevertheless:

here we are, sentient beings paying daily in pain for being such, cleaving to a flying ball of matter which is but part of a hurtling system of spherical clods hung, we know not how, in endless space. ${ }^{38}$

Is that it? Is this all that can be said? No. Some physicists have offered an account of how we got here. The most modern account of the generation of the universe is the Big Bang theory of the creation of the universe and, while popular, it cannot possibly be true. My objection lies not with the physics, or the mathematics, of the argument but rather with the logic of the argument.

The basic argument is that something of "zero size,"39 a singularity --- which is defined as "a point in space-time at which the space-time curvature becomes infinite ${ }^{40}$-.went bang and the universe came into existence. I have to ask: what is the difference between something of "zero size" and nothing? Consider something very small, say a grain of wheat. ${ }^{41}$ I can cut it in half and I would end up with two pieces. Can something of "zero size" be cut in half such that I would end up with two pieces like the grain of wheat? It seems not for zero divided by any number is zero. Size is a logically necessary concept; if something exists it must be of

36 Sheler, Jeffery L. "Hell Hath No Fury" in U. S. News \& World Report, January 31, 2000, p. 45.

37 https://tierneylab.blogs.nytimes.com/2009/06/12/the-physics-ofnothing/.

38 Sumner, William Graham and Keller, Albert Galloway. The Science of Society, Yale University Press, New Haven, Vol. 3, p. 2174.

39 Hawking, op cit, p. 147. He writes "At the big bang itself the universe is thought to have had zero size, and so to have been infinitely hot." I pause to note that Stephen Hawking died Wednesday, March 14, 2018 at the age of 76 .

40 Hawking, op cit, p. 242.

41 Locke, John. An Essay Concerning Human Understanding, Dover Publications, Inc., New York, 1959, Vol. 1, p. 169. 


\section{Philosophy International Journal}

some size.

Stephen Hawking seems to recognize the existence of logically necessary concepts when he writes "An event is something that happens at a particular point in space and at a particular time." ${ }^{\prime 2}$ All events occur somewhere and at some time. The Big Bang is an event. Therefore it must have occurred somewhere and at some time. But according to Hawking space and time began with the Big Bang. He writes that an illustration "shows the early universe, with some of the galaxies dating back to less than a billion years after the beginning of space and time." ${ }^{43}$

Logically it makes no sense to say that space and time had a beginning because if there was no space and time before the Big Bang there could be no space and no time for the Big Bang to occur. It is analogous to the Cleopatra example. While one could argue about the number of men she is reported to have had sex with, one cannot argue that if she had sex she had it no where and at no time, and with no one. That would be absurd as believing one of Jesus' foreskin becoming one of the rings of Saturn. At least the foreskin would have been of some size, even though it could not become one of the rings of Saturn. The proponents of the Big Bang theory would have us believe that some thing of

"zero size" went bang, no where and at no time, and became the entire universe.

The idea that the space and time came into existence with the creation of the universe dates back to St. Augustine in the 4th century. He wrote that "the world and time had both one beginning ... the world was made, not in time, but simultaneously with time." In addition he rests this claim on the "infallible Scriptures" that say "that in the beginning God created the heavens and earth." ${ }^{44}$

However, Lucian had rejected this account of time two centuries earlier when he hinted at the idea of logically necessary concepts when he wrote "it is by no means obvious how there could be place or time before the universe came into being." It is obvious if you understand that some concepts --- place and time --- are logically necessary concepts. Thomas Paine wrote that

The sublime and the ridiculous are often so nearly related that it is difficult to class them separately. One step above the sublime makes the ridiculous, and one step above the ridiculous makes the sublime

\footnotetext{
42 Hawking, op cit, p.34
}

43 The first illustration has no page number but it comes immediately after the page of the books "Contents."

44 St. Augustine, The City of God, Book X1, 6, trans. Marcus Dods (New York, Hafner Publishing Company, 1948) pp. 442-443. again. ${ }^{45}$

But three steps beyond the ridiculous --- that something of "zero size" went bang at nowhere and at no time ---becomes ludicrous especially when the proponents of the Big Bang theory of the creation of the universe rested their arguments on the Augustinian conception of time.

It is not enough to demonstrate that one theory is wrong unless one can present a plausible alternative. I now turn to explain this plausible alternative. This alternative can explain how the universe came to be what it is now without the absurdity evidenced by the Big Bang. Recall that by the universe I mean "everything that exists" whether known or unknown. Imagine the universe several billion years ago and call it state A. Now imagine the universe a few billion years later and call it state B. Now imagine the universe as it is now and call it state $C$. Recall the argument that there are necessary and sufficient conditions for all things, Since there are necessary and sufficient conditions for everything and the universe went from state $A$ to state $B$ and from state $B$ to state $C$, we have a complete account of how the universe came to be what it is now.

We can apply the same arguments to some parts of metaphysics. The word "metaphysics" or "metaphysical" is but another example of a word we reject. In ancient philosophy, the word "metaphysical" was introduced to describe what came after Aristotle's Physics. "(Meta, here, is Greek for after.)" To the unwary this opens a host of philosophical problems. To the wary, rejecting the terms metaphysics and metaphysical, closes the aforementioned host of philosophical problems. Thus we can reject the problems of mind and soul. Notice we don't reject these problems because we reject the notion of metaphysics. Rather we have alternative arguments for rejecting them, the absence of any evidence for their existence. There have been hundreds of thousand of human autopsies --- if not millions of them --- and not one of them listed the mind or the soul in any of them.

That something --- the soul and the mind --- has existed for a long time is not necessarily a good reason for rejecting it. However, when an idea has existed for so long and there is no evidence for its existence, then that is a good reason for rejecting it. Think about how long the idea of the flat earth society had existed. We, that is --- those who did not suffer from cultural lag --- rejected the idea of the flat earth society shortly after Columbus' voyage to the "New World."

Aristotle's idea of metaphysics assumes that there is

45 Paine, Thomas. The Age of Reason, The Truth Seeker Company, New York, 1898, p. 92. 
something "after" physics. But what if there is nothing after physics? Our idea of logically necessary concepts proves that if something exists it must exist somewhere and at some time. That is, it must be measurable or quantifiable for that is how we know that it exists. If something is not measurable, or to use Hawking's example, "zero size," how can we tell if it exists? We cannot. The idea is absurd as the doctrine of the "Divine Right of Kings." . That is, the king's reign was understood to have been appointed by God himself. The problem with this doctrine of the Divine Rights of Kings --- as logic informs us --- is that there can only be such a doctrine if there is a God. Since no one, in the history of human existence, has proven that God exists the doctrine is as absurd as the claim --- and for the same reason --- that the Bible is the word of God.

The same kind of argument explains how we went from a planet with no life on it to a planet with life on it. The necessary and sufficient conditions for life to occur must have existed, for if they did not exist there would be no life now. There is life now so therefore we know that the necessary and sufficient conditions must have existed. I concede that I do not know what those conditions were but it is not the task of a philosopher to know what they were; it is only the task of philosophers to know that they were. To know what they were belongs to scientists.

The same argument can be made with respect to epistemology. There was a time when there was no knowledge on this planet. There is knowledge now; for example, we just recently landed on the planet of Mars. Therefore there must be necessary and sufficient conditions for knowledge.

After proving the "big bang" cannot possibly be true and, after having demonstrated a rational alternative of how the universe came to be what it is, and after demonstrating how life began, and after escaping the fate of Ahasuerus, I can stand with Virgil when he wrote

Happy the man who doth the causes know Of all that is: serene he stands, above All fears; above the inexorable Fate, And that insatiate gulph that roars below. ${ }^{46}$

46 Robertson, John M. (Editor). The Philosophical Works of Francis Bacon, George Routledge and Sons Limited, New York, 1905, p.72. 